\title{
El Derecho de acceso a la información en Iberoamérica y su concreción como garantía constitucional. El caso mexicano
}

\author{
The right of access to information in Latin America and its \\ materialization as constitutional guarantee. The Mexican case
}

\author{
Guillermo A. Tenorio Cueto \\ Universidad Panamericana \\ gtenorio@up.edu.mx
}

\section{RESUMEN}

El presente trabajo se encuentra destinado a realizar un recorrido por los principios comunes de la transparencia y el acceso a la información en Iberoamérica estableciendo las condiciones teóricas fundamentales que justifican la existencia del derecho tratado iniciando por el impacto que tiene en el espacio y opinión pública y pasando por su íntima relación con la libertad de expresión y abordando los principios que nutren al derecho de acceso a la información y que son recogidos por la totalidad de legislaciones en toda Iberoamérica. El trabajo aborda las garantías para su ejercicio abarcando el concepto de autonomía de los órganos garantes que posibilitan una adecuada vivencia del derecho de acceso así como los procedimientos, responsabilidades y sanciones de su ejecución en los diversos sistemas. De igual manera mostramos el particular caso mexicano a partir de las carencias que, durante casi quince años supuso el acceso a la información en dicho país y como superó diversos obstáculos para proponer un sistema que permita a todos los ciudadanos del país gozar de una estandarización de procesos en todas las competencias del Estado y con ello potenciar en sentido igualitario el derecho de acceso a la información.

\section{PALABRAS CLAVE}

Transparencia, derechos de acceso a la información, derecho a la información.

\begin{abstract}
The article is destined to make a tour of the common principles of transparency and access to information in Ibero-America, establishing the fundamental theoretical conditions that justify the existence of the treated right, beginning with the impact it has on space and public opinion and Through its close relationship with freedom of expression and addressing the principles that nourish the right of access to information and which are collected by all legislation throughout Latin America. The work deals with the guarantees for its exercise encompassing the concept of autonomy of the guaranteeing bodies that allow an adequate experience of the right of access as well as the procedures, responsibilities and sanctions of its execution in the different systems. In the same way, we show the particular Mexican case, based on the shortcomings that, for almost fifteen years, the access to information in that country meant and how it overcame various obstacles to propose a system that allows all citizens of the country to enjoy a standardization of Processes in all the competencies of the State and with that to promote in an equalitarian sense the right of access to the information.
\end{abstract}

\section{KEYWORDS}

Transparency, rights of access to information, right to information. 


\begin{abstract}
SUMARIO
INTRODUCCIÓN. PRIMERA PARTE: I. LIBERTAD DE EXPRESIÓN Y DERECHO DE ACCESO A LA INFORMACIÓN. II. PRINCIPIOS QUE IRRADIAN LA CONSTRUCCIÓN DEL DERECHO DE ACCESO A LA INFORMACIÓN. III. CONTENIDO MATERIAL DEL DERECHO DE ACCESO A LA INFORMACIÓN. IV. GARANTÍAS PARA UN ADECUADO EJERCICIO DEL DERECHO DE ACCESO A LA INFORMACIÓN. SEGUNDA PARTE: EL CASO MEXICANO. I. UN ACCESO DESIGUAL, PRIMER RECORRIDO MEXICANO. A) TRANSPARENTAR SÍ PERO NO A RANGO CONSTITUCIONAL. B) TRANSPARENTAR SÍ PERO CADA QUIEN EN SU COMPETENCIA. II. LOS RETOS DE LA NUEVA LEY GENERAL. A) UN PASO PREVIO. B) ALLANANDO EL CAMINO. LOS PRIMEROS PASOS HACIA UNA LEY GENERAL DE TRANSPARENCIA. C) LOS PROBLEMAS CONCRETOS QUE ENFRENTARÍA UNA LEY GENERAL DE TRANSPARENCIA. III. ACCESO A LA INFORMACIÓN Y TRANSPARENCIA PARA TODOS. A) PRIMER RETO: SUPERAR EL FANTASMA DEL CENTRALISMO. B) MÁS INFORMACIÓN PÚBLICA EN POSESIÓN DEL CIUDADANO. C) LA CONCRECIÓN DEL ACCESO UNIVERSAL HOMOGÉNEO: PLATAFORMA NACIONAL DE TRANSPARENCIA. IV. ¿A MAYOR ACCESO A LA INFORMACIÓN, MEJORES CIUDADANOS Y MEJOR GOBIERNO?. CONCLUSIONES. BIBLIOGRAFÍA.
\end{abstract}

\title{
INTRODUCCIÓN
}

Se ha vuelto un lugar común en todos los sistemas de corte democrático o que aspiren a serlo el proponer al derecho de acceso a la información como un estandarte de su actuar en función del impacto que tal derecho tiene en la adecuada construcción de un espacio público pujante, deliberativo, crítico y sobre todo inclusivo. En ese sentido es importante entender que «el derecho de acceso es una herramienta fundamental para la construcción de ciudadanía» ${ }^{1}$

El derecho que nos ocupa en este trabajo perfecciona la vida democrática de cualquier sistema al contrarrestar por un lado los efectos nocivos de la corrupción y el autoritarismo ${ }^{2}$ propiciando la difusión de la información de manera completa y oportuna, haciéndola llegar de manera institucional al ciudadano restableciendo con ello el flujo de comunicación entre poder político y espacio público, y por otro al potenciar que la información encuentre a su legítimo propietario: el ciudadano.

El derecho de acceso a la información no es un derecho a recibir información que implica una especie de «derecho a la noticia» por el contrario, este derecho «no se reduce a un simple reflejo pasivo de la libertad de informar como simple interés difuso de la colectividad a acceder a la información ${ }^{3}$ sino adquiere fuerza y naturaleza propia en el «principio democrático, que reclama la publicidad de la información que obre en poder del Estado ${ }^{4}$, la cual debe existir de manera fehaciente y sin ningún tratamiento de edición o de selección de la información permitiendo con ello que el ciudadano acceda a la fuente primigenia, real, originaria de la misma.

Este derecho que hoy nos ocupa es un derecho que impone obligaciones a los poderes públicos orillándolos a publicitar su actuar no sólo a partir de un ejercicio material del mismo derecho sino a partir del establecimiento y reconocimiento constitucional de los sujetos obligados a proporcionar información y de las obligaciones que se asumen respecto a la misma.

Este trabajo estará orientado en dos partes. La primera parte la hemos destinado ha realizar un recorrido por los principios comunes de la transparencia y el acceso a la información en Iberoamérica y la hemos dividido en cuatro apartados. El primero de ellos vinculado a las libertades informativas como asidero del derecho que pretendemos estudiar. En dicho apartado estableceremos las condiciones teóricas fundamentales que justifican la existencia del derecho tratado iniciando por el impacto que tiene en el espacio y opinión pública y pasando por su íntima relación con la libertad de expresión. En un segundo momento abordaremos los principios que nutren al derecho de acceso a la información y que son recogidos por la totalidad de legislaciones en toda Iberoamérica, principios que delimitan, orientan, ilustran, el camino sinuoso por el que tendrá tránsito el derecho de acceso de cara a los poderes públicos. En tal apartado hemos delimitado el estudio a trabajar sólo con a) principio de máxima publicidad, b) principio de calidad de la información, c) principio de no discriminación, d) principio de gratuidad y, e) principio de buena fe. El tercer apartado lo

$1 \mathrm{CIDH}$, El derecho de acceso a la información pública en las Américas. Estándares Interamericanos y comparación de marcos legales, Relatoría especial para la libertad de expresión. OEA, 2012, pág. 1.

2 Idem.

3 FERNÁNDEZ RAMOS, Severiano, El derecho de acceso a los documentos administrativos, Marcial Pons, Madrid, 1997, pág. 23.

4 Idem. 
hemos destinado al contenido material del derecho de acceso en donde pretendemos delimitar los alcances del mismo como derecho universal de frente a los poderes del Estado en donde la celeridad, la oportunidad, la accesabilidad y la información completa son esenciales para una adecuada vivencia del mismo.

Hemos decidido cerrar esta primera parte del trabajo con las garantías para su ejercicio. En dicho apartado pretendemos abarcar el concepto de autonomía de los órganos garantes que posibilitan una adecuada vivencia del derecho de acceso así como los procedimientos, responsabilidades y sanciones de su ejecución en los diversos sistemas.

La segunda parte del presente trabajo tiene como finalidad proponer un análisis crítico del caso mexicano a partir de las carencias que, durante casi quince años supuso el acceso a la información en nuestro país pues siendo que México se consideraba como un país de avanzada en la materia de la transparencia y acceso a la información, también es cierto que en la instrumentalización de la política pública en la materia en todo el país, dejaba mucho que desear respecto a la real garantía de este derecho. Esta segunda parte pretende abordar la forma en la que México tuvo que superar diversos obstáculos para proponer un sistema que permita a todos los ciudadanos del país gozar de una estandarización de procesos en todas las competencias del Estado y con ello potenciar en sentido igualitario el derecho de acceso a la información. De igual manera pretendemos evidenciar que la obligación de transparentar en sede de la función administrativa del Estado también se vio afectada pues la estandarización de procesos impulsó a todos los llamados sujetos obligados, a cumplir con procesos de efectiva garantía sobre la publicidad de la información. Hemos dividido esta parte en cuatro apartados donde pretendemos sintetizar los importantes momentos del camino que ha llevado a México a esta referida estandarización de procedimientos para colmar de manera igualitaria el derecho de acceso a la información hacia toda la población.

\section{PRIMERA PARTE}

\section{LIBERTAD DE EXPRESIÓN Y DERECHO DE ACCESO A LA INFORMACIÓN}

Hablar de derecho de acceso a la información es hablar del conjunto de libertades informativas que nutren y colman el espacio donde se debate lo público. En ese sentido hablar del derecho a la información o el derecho de acceso a la información es hablar de dos componentes esenciales para la democracia contemporánea. Mientras el derecho a la información permitirá el recibir o difundir ideas de cualquier índole ${ }^{5}$ nutriendo con ello el espacio público ${ }^{6}$ de racionalidad estatal para su debate, crítica, interpretación o valoración, el derecho de acceso a la información propiciará que el ciudadano acuda directamente al Estado a buscar, investigar o indagar la información cuya única fuente es el poder público. Así, uno y otro nutren la vida democrática de los sistemas políticos que buscan tener esa vocación.

La libertad de expresión se nutrirá de ambos derechos dinamizando la llamada opinión pública ${ }^{7}$. Como sabemos esta llamada "opinión pública» tiene un componente esencial que es la información pues sin ella sería incapaz de suscitar un diálogo fecundo de crítica al poder público. La opinión pública tiene dos maneras de hacerse de la información: a) mediante el flujo continuo que hace el Estado a través de los intermediarios (medios masivos de comunicación) o bien a través de la publicidad propia del poder estatal mediante la publicación de determinados actos como las leyes o las sentencias. En esa dinámica el derecho a la información cobra vida pues genera la exigencia de recepción de información y, b) mediante el ciudadano que acude directamente con el Estado a exigir la entrega de determinada información para con ello poder inundar lo público. En este caso el derecho de acceso a la información será el actor principal.

\footnotetext{
${ }^{5}$ Así lo podemos encontrar en algunos autores como: LÓPEZ AYLLÓN, Sergio, Democracia y Acceso a la Información, Colección de cuadernos de Divulgación sobre Aspectos doctrinarios de la Justicia electoral, núm. 9, edit. Tribunal Electoral del Poder Judicial de la Federación, México, 2005, pág. 29.; ROMERO COLOMA, Aurelia María, Derecho a la Información y libertad de Expresión, edit. Bosh, Barcelona, 1984, pág. 56.

${ }^{6}$ Sobre la noción espacio público se pueden consultar entre otros: HABERMAS, Jürgen, Historia y crítica de la opinión pública, Gili, Barcelona, 2004; ARENDT, Hannah, La condición Humana, Paidos, Madrid o SAHUí, Alejandro, Razón, espació público en Habermas, Arendt y Rawls, Fontamara, México.

7 Sobre una aproximación a la noción de opinión pública se puede consultar: NOELLE-NEUMANN, Elizabeth, La espiral del silencio. Opinión pública nuestra piel social. PAIDOS, Buenos Aires, 1995.
} 
Ambos mecanismos potencian el desarrollo armónico del espacio democrático que tendrá como finalidad colmar al ciudadano de información para que éste pueda tomar adecuadas decisiones públicas. Mientras el derecho a la información asume que el ciudadano recibirá de manera pasiva la información, el derecho de acceso fomenta el activismo participativo con el objeto de propiciar una ciudadanía de mayor envergadura política ${ }^{8}$.

Ambos derechos se encuentran insertos en la médula de las libertades informativas, las cuales tienen su asiento en al consagrada libertad de expresión, la cual se nutre y a su vez nutre este espacio deliberativo democrático a partir de todo el enramado comunicativo que se da en sus entrañas. La libertad de expresión se compone de tres facultades, la de recibir, la de manifestar y la de investigar. Nuestro derecho de acceso encontrará surgimiento en esta última facultad donde le otorga al ciudadano el mecanismo idóneo para vincularse directamente con lo público, a través de la información que nos interesa a todos.

El derecho de acceso a la información no se encuentra separado de la libertad de expresión por el contrario la potencia al propiciar en el Estado la obligación positiva de suministrar información ${ }^{9}$, es decir, este derecho de acceso ocasiona en el poder público la significación de apertura de las fuentes de información pública ${ }^{10}$ generando con ello un «debate público amplio, robusto y desinhibido...basado en la información necesaria para que sea un debate inteligente y tenga sentido» ${ }^{11}$.

Así pues, la libertad de expresión como asiento de todo sistema democrático, genera el derecho de acceso a la información el cual se complementará de la obligación del Estado de transparentar activamente la información al ciudadano. La transparencia activa estatal ayudará a la libertad de expresión a colmar los dos derechos que hemos venido refiriendo en este apartado y en concreto con el derecho de acceso jugará un papel muy relevante al facilitar la información que por derecho le pertenece al ciudadano.

\section{PRINCIPIOS QUE IRRADIAN LA CONSTRUCCIÓN DEL DERECHO DE ACCESO A LA INFORMACIÓN}

El derecho de acceso a la información es movido por determinados principios que orientan su garantía. En ese sentido sabemos que el mencionado derecho se encuentra orientado a convertirse en esa «prerrogativa de toda persona para acceder y examinar datos y registros públicos en poder de los sujetos obligados» ${ }^{12}$ contribuyendo entre otros aspectos a «promover tanto en los ciudadanos como en las autoridades... las mejores condiciones para la toma de decisiones» ${ }^{13}$.

Podríamos hacer un listado de principios que de alguna manera inciden en el derecho de acceso pero hemos decidido centrarnos en los cuatro principio comunes a prácticamente toda la legislación Iberoamericana y que sirven de piso mínimo al quehacer de nuestro derecho de cara al titular y desde luego de cara al poder público traducido ya en autoridades que deberán protegerlo.

\section{a) Principio de máxima publicidad}

En su estudio sobre la burocracia, Max Weber nos ofrece una clara radiografía de la necesidad del secreto en el mundo de la burocracia de la administración pública. Refiere que la misma «...siempre propende a ser una administración de sesiones secretas; tanto como sea posible, hurtan a toda crítica sus conocimientos y actividades. La idea de secreto oficial es un invento específicamente burocrático y la burocracia defiende fanáticamente ese sigilo, el cual sólo puede justificarse esencialmente en ámbitos específicamente precisos» ${ }^{14}$. Sin lugar a equívocos uno de los principios de mayor calado y mayor necesidad en materia de acceso a la información será el principio de máxima publicidad el cual, estará orientado a romper con el sigilo, secreto o discrecionalidad del poder público.

8 Cfr. FAÚNDEZ LEDEZMA, Los límites de la libertad de expresión, IIJ-UNAM, México, 2004, pág. 746.

9 Corte Interamericana de Derechos Humanos, caso Claude Reyes vs Chile, parr. núm. 77.

10 Cfr. AZURMENDI, Ana, "La libertad de expresión en la jurisprudencia de la Corte Interamericana de Derechos Humanos: La influencia del tribunal europeo de derechos del hombre", en TENORIO CUETO, Guillermo, La libertad de expresión y sus fronteras contemporáneas, Porrúa-UP, México, 2007.

11 Cfr. FAÚNDEZ, op. cit., pág. 115.

12 Cfr. VILLANUEVA, Ernesto, Temas selectos de derecho de la información, IIJ-UNAM, México, 2004, pág. 20.

13 Idem.

14 Cfr. WEBER, Max, ¿Qué es la burocracia?, Ediciones Coyoacán, México, 2004, págs. 92 y 93. 
El principio de máxima publicidad permite entender que ab initio toda la información que obra en manos del Estado debe presumirse pública y accesible ${ }^{15}$, es decir que no basta con la generación de esquemas de publicidad sino que el principio adquiere una dimensión mayor la cual consiste en que el titular del derecho acceda a la información y pueda hacerlo de manera simple, rápida y sobre todo que no implique una información en lenguaje críptico que impida el entendimiento de dicha información, en otro sentido «..a la máxima publicidad no sólo hay que evidenciarla, hay que traducirla en actos que la hagan posible» ${ }^{16}$.

Como adelantábamos este principio se encuentra vinculado al objeto del derecho que es la información pública pero también al sujeto titular del mismo. El principio de máxima publicidad «impone al Estado no solamente una obligación negativa consistente en el deber de abstenerse de toda práctica que tenga por resultado retacear la accesibilidad pública a la información, sino también una obligación positiva consistente en adoptar medidas necesarias para asegurar que este derecho pueda ser ejercido en la práctica por cualquier ciudadano» ${ }^{17}$.

Este principio al igual que sucede con el derecho de acceso a la información y como sucede también con la libertad de expresión, no es de cuña absoluta sino que se mueve por el principio de relatividad, es decir que admite limitaciones. Estas limitaciones no significan un quehacer arbitrario del Estado para su imposición, por el contrario, estas limitaciones se encuentran debidamente orientadas, al menos en el ámbito internacional por las mismas reglas que para otras libertades informativas, es decir que:

a) El derecho de acceso a la información debe estar sometido a un régimen limitado de excepciones, el cual debe ser interpretado de manera restrictiva, de forma tal que se favorezca el derecho de acceso a la información.

b) Toda decisión negativa debe ser motivada y, en ese sentido, corresponde al Estado la carga de probar que la información solicitada no puede ser revelada; y

c) Ante una duda o un vacío legal, debe primar el derecho de acceso a la información ${ }^{18}$.

De igual manera habría que resaltar la imperante necesidad de que el establecimiento de limitaciones deberá encontrarse sujeto a un sistema muy estricto de excepciones, las cuales siempre deberán haber sido fijadas en ley de manera previa, buscando objetivos legítimos y ser necesarias en una sociedad democráti$\mathrm{ca}^{19}$. Ante ello, es decir, ante lo reducido en la posibilidad del establecimiento de limitaciones cabría afirmar que el principio de máxima publicidad tendría como punto de partida la idea de que el derecho de acceso a la información será la regla y el secreto o la información clasificada como reservada, la excepción.

A la par de este primer alcance del principio de máxima publicidad que hemos enunciado en el párrafo anterior es imperante señalar que el mismo obligará al Estado a probar el porqué de la limitación. En efecto, hemos venido diciendo que la máxima publicidad no es un principio absoluto sino que admite limitaciones y las mismas no quedan sujetas a un ejercicio arbitrario del poder, por el contrario deberán ceñirse a las reglas expresadas anteriormente quedando como carga al poder público el demostrar su necesidad.

De igual manera sucede cuando el derecho de acceso a la información entra en conflicto con algún otro derecho, o bien exista falta de regulación del mismo, el principio de máxima publicidad generará en automático la preminencia de aquel sobre cualquier otro derecho en conflicto. «Esta exigencia ayuda a promover que los Estados cumplan efectivamente con la obligación de establecer una ley de acceso a la información pública y que la interpretación resulte efectivamente favorable al derecho de acceso» ${ }^{20}$.

\section{b) Principio de no discriminación}

El segundo de los principios orientadores del derecho de acceso a la información es el llamado principio de no discriminación o principio de universalidad respecto al titular del derecho.

15 Corte Interamericana de Derechos Humanos, caso Gomes Lund y otros vs Brasil, parr. núm. 202.

16 BUSTILLOS ROQUEÑI, Jorge, "Máxima publicidad y reserva de la información como excepción", en CARBONELL, Miguel, Hacia una democracia de contenidos. La reforma constitucional en materia de transparencia, UNAM-IFAI-INFODF, México, 2007, pág. 51.

17 GUTIÉRREZ COLANTUONO, Pablo Ángel, "El acceso a la información pública - Una doble mirada convencional y del derecho argentino", en VALIM, Rafael, et al., (coords.), Acesso à informacão pública, FORUM, Belo Horizonte, 2015, pág 198.

18 Organización de Estados Americanos, El derecho de acceso a la información pública en las Américas. Estándares interamericanos y comparación de marcos legales, Relatoría especial para la libertad de expresión - CIDH, 2012, pág. 6.

19 GUTIÉRREZ, op. cit., pág. 199.

20 Organización de Estados Americanos, op. cit., pág. 24. 
Este principio se origina a partir de la misma universalidad de la libertad de expresión y se traduce en una legitimación activa no en función de la ciudadanía o algún interés jurídico demostrable sobre la información. Esta legitimidad activa de cualquier persona proviene justamente del carácter público de la información. En ese sentido «en prácticamente todas las leyes contemporáneas de acceso a la información no es necesario acreditar algún interés directo ni demostrar ningún tipo de afectación personal» ${ }^{21}$.

El principio que nos ocupa origina que los poderes públicos publiciten sus actos más allá de quien sea el interesado pues la información al ser pública deberá ser puesta en disposición del público indistintamente sea ciudadano, sea extranjero, sea mayor de edad o utilice un pseudónimo para recabarla, el poder público no deberá generar ningún tipo de discriminación para entregarla pues la naturaleza de ella es justamente ser pública.

De este principio derivamos diversas obligaciones al Estado entre las cuales destacamos a) No podrá negarse el derecho a la información pública gubernamental a ninguna persona por cualquier distinción, exclusión o restricción por cualquier motivo que atente contra la dignidad humana y tenga por objeto anular o menoscabar los derechos y libertades de las personas, b) Tampoco se podrá denegar la realización de ajustes razonables para acceder al derecho a la información, c) Para que todas las personas puedan acceder a la información pública gubernamental en igualdad de oportunidades y sin discriminación alguna, las instituciones del Estado mexicano deberán eliminar las barreras que impidan el acceso en los hechos, de modo que deben implementar medidas positivas y compensatorias para hacer efectiva su realización, d) En la realización del derecho a la información pública gubernamental, las instituciones deberán observar el principio de máxima publicidad y disponibilidad de la información, esto debe considerar las necesidades de las personas con discapacidad, e) Toda persona tendrá acceso gratuito a la información pública, a sus datos personales o a la rectificación de éstos ${ }^{22}$.

Universalidad o no discriminación juegan un papel preponderante en el ejercicio del derecho de acceso a la información al situar en el centro del mismo a toda persona humana propiciando que la entrega de la información, incluso, alcance a aquellas personas que por determinadas circunstancias se encuentren limitadas de sus capacidades físicas, tal como se desprende del párrafo anterior.

\section{c) Principio de calidad de la Información}

El tercero de los principios que irradia el enramado del derecho de acceso a la información, es el principio de calidad de la información. Este principio se suma a los otros dos aportando una característica esencial de la información: su calidad.

La calidad de la información estará vinculada a diversas obligaciones por parte de los órganos públicos. En ese sentido por calidad deberemos entender, a) información actualizada, b) información completa, c) información comprensible y d) información veraz. De nada serviría el derecho de acceso sin estos atributos en la información que se entrega, pues una información poco actualizada, incompleta, poco o nada comprensible o falaz sólo producirían un efecto de ocultismo en el Estado siendo justamente lo que se busca evitar ${ }^{23}$.

Este principio encontrará actualidad en dos dimensiones, por un lado desde la óptica de la llamada transparencia activa de la información donde el Estado deberá publicitarla como parte de su obligación de transparentar ${ }^{24}$ y por otra desde la óptica del derecho de acceso donde, a partir de una solicitud de información el Estado deberá entregar la información. En ambos casos, el principio de calidad de la información se actualiza.

Cada uno de los atributos referidos en los párrafos que anteceden tendrá alcances significativos. En el caso de la información actualizada nos lleva a entender que los sujetos obligados deberán periódicamente revisarla agregando los elementos presentes más relevantes que puedan ayudar a la persona a tener un conocimiento real de la situación de la información solicitada. De nada serviría colocar información vetusta que en nada contribuya a la toma de decisiones presente. Así, por ejemplo, si pretendiéramos obtener la

21 VILLANUEVA, Ernesto, Derecho de acceso a la información pública en Latinoamérica, IIJ-UNAM, México, 2003, pág. LIV.

22 IFAI, Información, accesibilidad, diversidad e interacción, México, 2011.

${ }_{23}$ El tema de la calidad de la información fue trabajado en 2010 por la Corte Interamericana de Derechos Humanos en el caso Gómez Lund y otros vs Brasil en donde los solicitantes piden esclarecer las circunstancias de las desapariciones forzadas de sus familiares. A ello el Estado de Brasil respondió con un sinfín de información en donde no se detallaba una respuesta clara a los solicitantes. La CIDH en su resolución obliga al Estado a realizar todas las acciones necesarias para precisar con más detalle la información. CIDH, Caso Gomez Lund y otros vs Brasil, de 24 de noviembre de 2010.

${ }^{24}$ Cfr. VILLANUEVA, Derecho de acceso... op. cit., pág. LIX. 
información del directorio de una dependencia pública, de nada nos servirían líneas telefónicas que ya no existan o direcciones en donde la dependencia ya no tenga oficinas.

Por su parte, cuando hablamos de la información completa nos referimos a un atributo de vital importancia para la calidad. Al igual que sucede con la actualización, los sujetos obligados deberán entregar la información que se les pide sin ambigüedades y sin regateos. Esto significa que si se solicita, por ejemplo, el monto del salario de un funcionario público lo que esperamos de la respuesta es justamente ello y no una información que nos refiera un salario base sin las compensaciones adicionales que integrarían la totalidad del mismo. Cuando hablamos de lo completo de la información estamos evocando un atributo que en caso de no cumplirse, supondría que la información no fue entregada pues de nada sirve una información incompleta para la toma de decisiones públicas o bien para la participación ${ }^{25}$.

El tercero de los atributos tiene que ver con la información comprensible. Sin este atributo el principio de calidad quedaría truncado. De nada nos serviría una información actualizada y completa si no la podemos comprender. En ese sentido, los sujetos obligados deberán establecer los mecanismos idóneos para que la información sea asequible para cualquier persona que la procese pues de no ser así esto supondría los mismos efectos de una información incompleta o poco actualizada, es decir, supondría que la información no fue entregada. De que serviría accionar el derecho de acceso si la información proveniente del sujeto obligado nos es entregada en un lenguaje críptico, inentendible u oscuro. El atributo de comprensibilidad es esencial al principio de calidad de la información al permitir establecer una acción comunicativa, asertiva, cierta y entendible.

El último de los atributos tiene que ver con la veracidad de la información. Este atributo no sólo estará ligado con el principio de calidad en la información sino también estará ligado con el principio de buena fe. La falsedad de la información o la manipulación de la información con un ánimo de engañar al solicitante supone no sólo la fractura del sistema de transparencia y acceso a la información sino supone la existencia de sujetos obligados que en nada viven el sentido democrático de la información. Podríamos referir que el incumplimiento de este atributo supone el claro quebrantamiento del Estado democrático pues el titular de la información carecería de la misma la cual es secuestrada por el poder político para los fines que este disponga ${ }^{26}$.

\section{d) Principio de gratuidad}

El último de los principios que exponemos en este trabajo es el principio de gratuidad. Este principio contribuye esencialmente a la cultura de transparencia, potenciando de manera significativa el interés de las personas por la búsqueda de información ${ }^{27}$. La gratuidad debe entenderse desde dos perspectivas: la primera de ellas vinculada a toda aquella información que es consultada y la segunda vinculada a toda aquella información que es reproducida y enviada. Sobre la primera es claro que el principio de gratuidad se actualiza a plenitud al tratarse de una información que es pública y que se evidencia en la vitrina de la información.

Por otro lado tenemos aquella información que es reproducida y enviada. Para tal caso el principio de gratuidad se encuentra con una excepción es decir, en este supuesto donde la información es depositada en algún contenedor especial y posiblemente enviada al titular del derecho, sí es factible el cobro pero sólo por el costo de reproducción y envío, procurando que dichos costos no sean excesivos fagocitando con ello la búsqueda de información ${ }^{28}$.

\section{CONTENIDO MATERIAL DEL DERECHO DE ACCESO A LA INFORMACIÓN}

\section{a) El derecho de acceso como derecho universal}

Uno de los primeros debates con los cuales nos enfrentamos cuando hablamos del derecho de acceso a la información es justamente delimitar los alcances de la legitimación de los sujetos que en el intervienen.

25 Organización de Estados Americanos, El derecho... op. cit., pág. 54.

${ }^{26}$ Sólo como muestra valdría revisar la doctrina en materia del concepto razón de Estado. Al respecto puede consultarse UVALLE BERRONES, Ricardo, La teoría de la razón de Estado y la administración pública, PyV editores, México, 1993.

27 Cfr. VILLANUEVA, Derecho de acceso... op. cit., pág. LVI.

${ }^{28} \mathrm{Idem}$. Refiere el autor que «Lo importante en este punto es que el precio sea accesible al mayor número de personas y tenga como único propósito el mantenimiento del servicio de búsqueda, reproducción y envío de materiales, sin perseguir en ningún caso, fines de lucro, ahorro o alguna ganancia para la entidad..... 
En ese sentido la primera distinción obligada a realizar es entre los sujetos activos y los sujetos pasivos que intervienen en dicho derecho. Por sujetos activos entenderemos a quien requiere la información, mientras que por sujetos pasivos entenderemos a quien se solicita la información ${ }^{29} \mathrm{El}$ objeto de este apartado será referirnos al titular dejando al siguiente la referencia al sujeto pasivo.

El derecho de acceso a la información, como ya veíamos en el capítulo precedente es un derecho humano de cuña universal ${ }^{30}$ es decir que «toda persona, sin consideración de fronteras tiene derecho a solicitar acceso a la información.... ${ }^{31}$ sin que medie una exigencia de legitimación sobre la misma. Esto nos lleva a suponer que el alcance de dicho derecho implica que la información pública, por tener esa cualidad, no necesita el reconocimiento o la demostración de interés sobre ella, dicha legitimidad se obtiene por el simple hecho de ser persona ${ }^{32}$.

El alcance de esta universalidad implica también la posibilidad de que la persona, titular del derecho, pueda utilizar la información para su divulgación inundando con ello el espacio público democrático e impactando con ello en la generación de opinión pública, donde esta analice, valore, interpreta o critique dicha información. Con ello «...el derecho de acceso a la información comparte así las dimensiones individual y social del derecho a la libertad de expresión, las cuales deben ser garantizadas simultáneamente por el Estado» ${ }^{33}$

\section{b) El derecho de acceso y los Ilamados sujetos obligados}

El segundo de los sujetos que intervienen en este derecho de acceso a la información son los llamados sujetos obligados. Como referíamos en líneas anteriores, los sujetos obligados serán los sujetos pasivos de este derecho, no por una razón de quietud sino por la especial relación que guardarán ante el titular del derecho es decir una relación de custodia, almacenamiento y puesta a disposición de la información que el titular requiere. El sujeto obligado en ese sentido deberá asumir responsabilidades y deberes respecto a la información y su calidad para que cuando el titular del derecho la requiera, ésta se encuentre disponible.

El sujeto obligado formará parte esencial de una adecuada política de transparencia, acceso a la información y rendición de cuentas pues de lo contrario el sistema encontraría una clara fractura. No basta con la suposición o intuición de quien deberá transparentar su actuar o quien deberá proporcionar acceso a la información, por el contrario debe, desde el texto constitucional vincularse al o a los poderes públicos susceptibles de ser condicionados por esta política que ahora ya se traduce en un derecho que es deber de toda autoridad garantizar. Así, «el derecho de acceso genera obligaciones para todas las autoridades públicas de todas las ramas del poder y de los órganos autónomos, de todos los niveles de gobierno» ${ }^{34}$.

Como podemos darnos cuenta, el estándar internacional se encuentra vinculado a la exigencia de obligatoriedad de toda autoridad pública en todos los niveles, propiciando con ello una vivencia a cabalidad del derecho de acceso a la información, pues sin ello, lo único que ocurriría sería un sistema de transparencia y acceso a la información asimétrico.

El diseño institucional de este derecho en ocasiones pone obstáculos como ha sido el caso de algunos países en donde se han implementado exclusiones o se han dejado algunos ámbitos del poder público fuera de la legislación que contempla a los sujetos obligados ${ }^{35}$ pero es claro que la construcción internacional del mismo prevé que se «...extiende a todos los órganos públicos en todos los niveles de gobierno, incluyendo a los pertenecientes al poder ejecutivo, al legislativo y al poder judicial, a los órganos creados por las constituciones o por otras leyes, órganos de propiedad o controlados por el gobierno y organizaciones que operen con fondos públicos o que desarrollen funciones públicas» ${ }^{36}$.

29 Cfr. VILLANUEVA, El derecho de acceso..., pág. XXVI.

30 OEA, El derecho... op. cit., pág. 32.

31 Idem.

32 OEA, El derecho... op. cit., pág. 32.

33 Idem.

34 Ibidem, pág. 37

35 Es el caso por ejemplo de Estados Unidos, véase FERNANDEZ RAMOS, El derecho..., op. cit., pág. 34, o bien el caso mexicano donde la evolución del derecho de acceso ha fomentado la inclusión en la legislación de mayor número de sujetos obligados e inclusive la creación de un sistema nacional de transparencia justamente para vencer las asimetrías presentadas entre el gobierno federal y las entidades federativas en donde se mostraba claramente que la vivencia del derecho de acceso a la información era desigual aún y cuando se había contemplado en la Constitución Política de aquel país.

36 OEA, El derecho de..., op. cit., pág. 38. 


\section{c) El objeto del derecho: la información pública}

Hemos venido hablando de los sujetos que intervienen en el derecho de acceso a la información y nos restaría hablar del objeto del mismo. En ese sentido es preciso delimitar la expresión «información pública». Alguna primera aproximación a dicho concepto estará vinculado justamente a aquella información manejada por los sujetos obligados, es decir que toda aquella información que ellos manejen deberá considerarse en la categoría que estudiamos.

En realidad el concepto de información pública adquiere varios matices. En principio hablamos de información que reposa o se sostiene en documentos administrativos en el sentido más amplio de la expresión es decir, que no sólo debemos referirnos al documento impreso en papel sino a cualquier asiento físico en donde recaiga la información ${ }^{37}$. Esta primera aproximación nos da idea del asiento físico pero pudiera confundirnos con el asunto del documento administrativo siendo que, para no entrar en confusiones podríamos decir que la información pública será toda aquella información producida por los agentes del Estado o por aquellas entidades o personas que no siendo agentes del Estado reciben recursos públicos asentada en cualquier soporte material y que impacta directamente en el espacio público para interpretarla, criticarla, debatirla o analizarla.

De igual manera por información pública nos referimos a información pasada o presente pero no a información futura que no encuentre asiento o que no exista en la realidad ${ }^{38}$. Esto no significa que por no tener asiento físico no deba existir una obligación de generarse, por el contrario en muchas ocasiones y luego de destruir la información el titular del derecho puede exigir la reconstrucción de la información ${ }^{39}$ al haberse generado la misma y destruido alevosamente o por falta de cuidado en su manejo. Pero el caso que referimos versa sobre información que nunca ha existido.

A la par de lo anterior la información pública adquiere determinadas características que orientadas por los principios enunciados en apartados precedentes completan el cuadro de lo que debemos entender por ella. Ellas son celeridad, la oportunidad, la accesibilidad e información completa.

La información pública debe entregarse con sentido de apremio pues ella en principio se encuentra disponible por lo cual no es entendible un retraso sólo es necesario contemplar el tiempo de búsqueda y entrega. En ese sentido la información la celeridad en la entrega constituye un elemento muy importante para el sano ejercicio del derecho de acceso a la información. El retraso en la entrega sólo puede justificarse a partir de caer en alguna de las excepciones del derecho de acceso en donde el análisis de la misma supone un tratamiento cuidadoso pero no eterno. Esto significa que, a pesar de considerar que la información pueda ser considerada como confidencial o reservada en ningún caso la respuesta puede suponer dilación injustificada.

Este tipo de información debe ser accesible y oportuna pues de lo contrario nos encontraríamos en la hipótesis de un tipo de información que se genera pero no inunda lo público. La información pública hace recaer su acento justo en el adjetivo «público» es decir que la información adquiere por esencia una naturaleza comprensible a toda persona interesada en conocerla y comprenderla. El carácter de oportunidad y accesibilidad potencia la calidad de la información al incidir directamente en la formación de la opinión pública. Sin la oportunidad y sin la accesibilidad este derecho de acceso a la información quedaría reducido a la nada.

Ya nos referíamos, cuando hablamos de los principios que orientan el derecho de acceso, a la información completa. Aquí no la veremos como principio sino como característica de la información. El titular del derecho busca información y esta no puede entregarse incompleta o reducida a una parte por voluntad del sujeto pasivo, por el contrario, la información debe entregarse completa, sin ambigüedades ni regateos por parte de la autoridad pues de entregarse disminuida deberá entenderse que no se ha entregado ${ }^{40}$.

\section{d) Límites del derecho de acceso}

Como sucede con cualquier otro derecho o libertad en los sistemas democráticos, estos adquieren una característica de relatividad, es decir que no son considerados absolutos pues admiten limitaciones o

37 FERNÁNDEZ RAMOS, El derecho..., op. cit., pág. 35.

38 Ibidem, pág. 36.

39 Cfr. VALDERRAMA CABRERA, Marcela, La reconstrucción de la información, Tesis de grado de Maestría en Derecho Administrativo, Universidad Panamericana, México, 2014.

$40 \mathrm{CIDH}$, Caso Gomez Lund y otros vs Brasil, de 24 de noviembre de 2010. 
restricciones. Sabemos también que estas restricciones no son una carta abierta para el poder público, por el contrario el estándar internacional en la materia ha elaborado un sistema que conocemos como el test tripartito en donde queda reducido el ámbito para el establecimiento en la libertad de expresión y por supuesto en todos los derechos derivados de ésta ${ }^{41}$.

En el caso del derecho de acceso a la información pública las limitaciones se encuentran normalmente contenidas a partir de dos supuestos: el primero de ellos a partir de la información que versa sobre la confidencialidad de las personas y el segundo a través de la información considerada como reservada para el poder público.

En el caso de la información que guarda especial relación con la vida privada o íntima de las personas la limitación se presenta como natural al ejercicio de la publicidad de la información. En este caso, es preciso la clasificación por tratarse de un bien jurídico que en ponderación con lo público no participara de dicho elemento. La información confidencial no es por esencia información pública y en nada abona a lo público. Puede ser que a partir de la información confidencial obtengamos datos estadísticos que nos sirvan para la decisión pública pero dicha utilización de la información estará supeditada a un proceso de disociación en donde la vida privada o íntima no sea menoscabada.

La información clasificada como confidencial no podrá ser nunca revelada. Es más, para efectos de este tipo de información, el poder público deberá en todo momento asumir una serie de mecanismos de seguridad para el debido resguardo y protección siendo que, desde su obtención, se deberá informar al titular de la información que se hará con ella, para que fines se obtiene, si será susceptible de divulgación y como se efectuará su almacenamiento.

La protección de información personal por parte del Estado debe ser garantizada más que como una limitación del derecho de acceso a la información como un derecho fundamental derivado del derecho a la vida privada a partir de lo que se denomina autodeterminación informativa.

La segunda limitante al derecho de acceso a la información es aquella información que el poder público decide clasificar como reservada ${ }^{42}$. Esta información a diferencia de la confidencial tendrá un carácter de temporalidad, es decir, no quedará en secreto o reserva por siempre, la característica esencial es que la información podrá ser difundida eventualmente pero en el momento presente no puede ser revelada pues dicha revelación podría causar un daño al entorno público.

En el caso de la información clasificada como reservada no hablamos de información privada, hablamos de información pública que por causas de fuerza mayor deberán quedar en sigilo y en manos únicamente del poder público por el daño que puede suponer su revelación en el entorno social. Los típicos ejemplos de este tipo de información son entre otros a) la seguridad nacional, b) la seguridad pública, c) las relaciones internacionales, d) la información proveniente de las actuaciones judiciales mientras no causen estado. Cada Estado establecerá las limitaciones vinculadas a la reserva que considere oportunas siempre y cuando, como lo referimos anteriormente, sean proporcionables y adecuadas para el cumplimiento de los estándares que en la materia se imponen.

La reserva de la información ${ }^{43}$ no rompe con el principio de máxima publicidad, por el contrario lo colma, pues como referimos con anterioridad, lo único que provocará será un cambio en el tiempo de entrega generando con ello que la información no entre en un estado de reserva definitivo sino que la información sólo adolezca de la temporalidad para su entrega. De igual manera es necesario precisar que la calificación de la reserva debe hacerse atendiendo siempre al daño que se puede efectuar debiendo existir no sólo la fundamentación de la reserva sino también la motivación para poder destacar de que manera se efectúa el daño. A la par de ello es preciso que para un adecuado ejercicio del derecho de acceso. Sobre todo vinculado a la información clasificada como reservada, es necesario contar con un órgano autónomo que verifique y analice si la calificación estuvo adecuadamente realizada. De ello hablaremos en el siguiente apartado.

41 OEA, Marco jurídico interamericano de la libertad de expresión, Relatoría especial para la libertad de expresión, OEA, 2010. El llamado test tripartito en materia de libertad de expresión contempla que para el establecimiento de limitaciones es necesario que la misma a) se encuentre redactada en ley de manera clara y precisa, b) que la limitación persiga objetivos legítimos y c) que la limitación sea necesaria para una sociedad democrática.

42 NAVA GOMAR, Salvador, "Información Reservada", en VILLANUEVA, Ernesto y LUNA PLA, Issa, Derecho de acceso a la información pública. Valoraciones iniciales, IIJ-UNAM, México, 2004.

${ }_{43}$ VILLANUEVA, El derecho de acceso..., op. cit., pág. LXXII. Refiere el autor que «...la información reservada se encuentra delimitada con un tiempo máximo derivado de plazos y/o eventos determinados. En el derecho comparado se puede observar que los plazas de reserva van desde los 5 hasta los 30 años y sujetos a que dentro de esos plazos la información pueda revelarse si dejan de existir las condiciones particulares que motivaron la reserva de la información...». 


\section{GARANTÍAS PARA UN ADECUADO EJERCICIO DEL DERECHO DE ACCESO A LA INFORMACIÓN}

\section{a) Como derecho fundamental}

El derecho de acceso a la información hemos dicho con anterioridad debe ser considerado un derecho humano fundamental y así debe ser tratado a nivel constitucional como ya lo es tratado a nivel convencional. El derecho de acceso a la información encontrará un revestimiento especial de protección cuando logra ser desglosado de la libertad de expresión y se deja plasmado como un derecho que impacta no sólo a la realización personal sino que tiene un impacto medular en la construcción de una sociedad democrática abierta, deliberativa y dialogante.

La protección que supone al derecho de acceso encontrarse dentro del llamado bloque de constitucionalidad supone un reconocimiento pleno a su autonomía para su debida protección. La persona vulnerada en su derecho de acceso podrá acudir no sólo a la justicia administrativa solicitando protección sino podrá lograr la judicialización del derecho y buscará su interpretación y aplicación constitucional impidiendo con ello que el mismo derecho quedara relegado a una mera interpretación de la libertad de expresión.

Esta entrada a la protección judicial abre una puerta gigante para el desarrollo de su contenido en sede jurisprudencial con lo cual los alcances que hoy no vemos del derecho de acceso puedan completarse en el futuro gracias a la interpretación constante que realizan los tribunales constitucionales en todo Iberoamérica.

\section{b) La autonomía del órgano garante}

Si bien es cierto el derecho de acceso obtiene una garantía de protección inicial al tratarse de un derecho fundamental también es cierto que por las características inherentes del mismo es un derecho que necesita de una especial protección al tratarse de un derecho que se efectúa directamente con el poder público. La tentación de ceñir la revisión de las negativas de información al mismo poder público que la niega son grandes.

En ese sentido es imperante precisar que un adecuado tratamiento del derecho de acceso debe venir acompañado de un órgano garante ajeno a las presiones e intereses del poder público, por ello, dicho órgano debe garantizar su autonomía y desvinculación a cualquier grupo político interesado en la dinámica de obtener el poder público ${ }^{44}$. Este órgano velará no sólo por la revisión de las negativas de la información sino que, por su carácter especializado, deberá velar por la promoción de una cultura de transparencia activa y proactiva de los sujetos obligados, por una adecuada cultura de promoción del derecho de acceso a la información en la ciudadanía y por supuesto por un fortalecimiento de su autonomía en el marco de una sociedad democrática.

La garantía que ofrece el órgano encargado de vigilar el sano desarrollo de este derecho, es mayúscula y propicia sin lugar a equívocos, certidumbre en el ejercicio del derecho. Por el contrario cuando vemos que es el mismo poder público el que realiza la revisión de las negativas de información observamos que el titular del derecho se desencanta de la posibilidad de accionarlo pues puede considerar que el derecho de acceso es una mera ilusión que no podrá concretarse.

\section{c) Los procedimientos ante los sujetos obligados y el órgano garante}

Teniendo un derecho fundamental y un órgano garante el desarrollo de los procedimientos en materia de acceso a la información deberán volcarse en algunos de los principios, características y atributos que hemos mencionado en los apartados precedentes. En ese sentido es imperante que los procedimientos que se establezcan a) vinculen directamente a los sujetos involucrados (activo y pasivo) b) sigan el atributo de celeridad, c) sean accesibles d) sean gratuitos y d) sean recurribles.

${ }^{44}$ BALTAZAR MACÍAS, Atzimba, GUERRERO AMPARÁN, Juan Pablo, "El Instituto Federal de acceso a la información pública: La construcción institucional”, en CONCHA CANTÚ, Hugo, et. al. (coords.), Transparentar al Estado: la experiencia mexicana de acceso a la información, IIJ-UNAM, México, 2005, pág. 40. 
El titular del derecho deberá en primer lugar relacionarse con el sujeto pasivo solicitando la información pública. El sujeto obligado deberá hacer una búsqueda en sus archivos canalizando adecuadamente la solicitud al área o áreas que puedan contener la información. En ese mismo acto de búsqueda el sujeto obligado, deberá en su caso hacer la precisión si la información adolece de alguna de las limitaciones para poder informar adecuadamente al titular del derecho. Para ello se debe establecer un tiempo de respuesta así como las posibilidades de ampliación de plazo o el re direccionamiento de la solicitud cuando el sujeto obligado no es el adecuado para solicitar la información.

Ante la negativa de la información es necesario contar con procedimientos que supongan que dicha resolución puede recurrirse objetando la negativa a la solicitud. Para ello el órgano garante autónomo, puede jugar un papel determinante pues el titular del derecho tendrá posibilidades de acceder a una revisión adecuada sobre el fundamento y la motivación de la negativa de la información.

Una vez agotados estos procedimientos es menester abrir la puerta a la tutela judicial efectiva potenciando el acceso del titular a una nueva interpretación del derecho de acceso en sede judicial. Con ello el derecho que nos ocupa adquiere un mayor revestimiento de protección y el diseño institucional de la política de transparencia y acceso a la información queda redondeado de manera adecuada.

\section{d) Las responsabilidades y sanciones de los sujetos obligados.}

Es inevitable referir que todo este sistema que engloba la transparencia y el derecho de acceso a la información quedaría muy limitado sino se extiende el brazo a la imposición de responsabilidades y sanciones. Es una pena observar en algunos sistemas donde se introduce una política de transparencia o se introduce el derecho de acceso a la información, que no se contemple para los servidores públicos que incurren en faltas, negligencia o dolo, un sistema de sanciones administrativas o penales para contrarrestar su agravio.

Si bien es cierto que la cultura de transparencia y acceso a la información debe asumirse en todo el entorno social potenciando la participación pública, también es cierto que debe existir incentivos a la administración pública y a todos los sujetos obligados en donde se fijen responsabilidades por un inadecuado manejo de la información.

Este tipo de sanciones y responsabilidades deberá establecerse de manera graduada y atendiendo al tipo de falta, negligencia o dolo y por supuesto atendiendo también al tipo de información que haya sido dañada, negada o difundida.

\section{SEGUNDA PARTE. EL CASO MEXICANO}

\section{UN ACCESO DESIGUAL, PRIMER RECORRIDO MEXICANO}

La intención de este apartado no busca hacer un exhaustivo recorrido por el itinerario de la construcción del marco jurídico mexicano en materia de transparencia sino por el contrario referir al lector los efectos que el marco jurídico en materia de acceso a la información y transparencia administrativa propiciaban respecto a una adecuada garantía en aquel derecho y de esta obligación del Estado. En ese sentido trataremos de construir un apartado crítico refiriendo los antecedentes, las causas y los efectos en cada uno de los aspectos que consideremos más relevantes respecto a la escasa garantía del derecho por parte del Estado Mexicano.

\section{a) Transparentar sí pero no a rango constitucional}

Luego de casi 70 años de un régimen de opacidad el Estado Mexicano incursiona por primera vez en materia de transparencia administrativa y derecho de acceso a la información al inicio del Siglo XXI. Los llamados nuevos aires democráticos que fueron marcados por una llamativa alternancia en el poder hacían suponer que México entraría de lleno a un proceso de una marcada transición a la democracia. Desde principio de los años noventa la presión internacional y la presión interna sobre transparentar el actuar del Estado Mexicano fueron realmente notables sólo hace falta recordar el trabajo que realizó el 
Ilamado Grupo Oaxaca para impulsar una agenda constante en materia de Transparencia y Acceso a la Información ${ }^{45}$.

El resultado de todo ese esfuerzo quedó plasmado en la primera Ley Federal de Transparencia y Acceso a la información gubernamental que promulgó y publicó el entonces Presidente Vicente Fox la cual tenía como vocación fundamental impactar en todos los órganos del Gobierno Federal para iniciar la construcción de toda una política pública nacional en la materia ${ }^{46}$. Este esfuerzo no fue menor y haciendo un adecuado reconocimiento sentó las bases para que en los años venideros no hubiera marcha atrás. El tema de transparencia y acceso a la información desde entonces no ha salido de la agenda de los gobiernos en México y hemos visto como se ha ensanchado.

Pero ese primer esfuerzo sin lugar a dudas fue insuficiente pues si bien es cierto el artículo $6 .^{\circ}$ de la Constitución mexicana fraseaba que «El derecho a la información sería garantizado por el Estado» era claro que ese derecho a la información no era el derecho de acceso a la información que hoy conocemos. La fragilidad con la que se sostenía la Ley federal de acceso a la información era notable pero suficiente para un primer esbozo de la protección del derecho máxime que la Suprema Corte de Justicia de la Nación durante la década anterior había ya ampliado la interpretación material de dicho enunciado dando cabida al incipiente derecho de acceso a la información ${ }^{47}$.

Aún y cuando el andamiaje constitucional era frágil se lograron los consensos políticos suficientes para que pudiera ver la luz la referida ley federal de transparencia, la cual incorporó de inmediato lo temas torales de una legislación en la materia los cuales eran: a) Obligaciones de transparencia, b) Sujetos obligados, c) Excepciones, d) Órgano garante; y e) Procedimientos ${ }^{48}$. Cada uno de ellos desarrollado en el cuerpo normativo y sirviendo de mínimo para construir un diseño institucional que pudiera orientar al resto de competencias.

\section{b) Transparentar sí pero cada quien en su competencia}

Esta construcción quedó ceñida sólo a los poderes federales dejando a las competencias locales o de las entidades federativas un amplio margen para que pudieran legislar sobre la materia en los términos que ellos quisieran. Era claro que la Ley Federal sólo serviría de marco referencial pero no obligaba. Por si fuera poco, la ley federal en materia de procedimientos sólo vinculaba al Ejecutivo Federal sobre quien recae primordialmente la función de la administración, dejando fuera a otros poderes de la Unión como el judicial y legislativo y a los nacientes organismos constitucionales autónomos como lo eran en aquel entonces el Comisión Nacional de Derechos Humanos, la UNAM, el Banco de México y el entonces llamado Instituto Federal Electoral ${ }^{49}$.

Con este escenario quien más padeció fue el derecho de acceso a la información pues si bien es cierto era uno de los temas centrales de toda la política pública que se estaba implementando, también es cierto que el reparto de competencias para el establecimiento de procedimientos dejaba un amplio margen para que el resto de los sujetos obligados fuera del ejecutivo federal pudieran no instaurar procedimiento alguno o bien si lo hacía hubiera un amplio margen para su elusión sin sanción.

45 Cfr. LUNA PLA, Issa, Movimiento social del derecho de acceso a la información en México, IIJ-UNAM, México, 2009 , pág. 70. Al respecto la autora refiere dicho grupo «... se caracterizó por la participación de los académicos en su vertiente ciudadana... Este grupo que promovió la ley federal, supo en que momentos utilizar las Universidades como espacio de debate y cuando llevar las fuerzas adquiridas hasta el Congreso de la Unión...».

46 Cfr. LÓPEZ AYLLÓN, Sergio, La creación de la Ley de Acceso a la Información en México: Una perspectiva desde el Ejecutivo Federal, IIJ-UNAM, México, 2004, pág. 5. Sobre el particular el autor nos refiere que «Una vez consolidad la democracia electoral, parecía necesario dar un paso adicional, que consistía en dar a los ciudadanos acceso a la información pública para que pudieran evaluar la gestión de su gobierno. Se trata de un mecanismo de transferencia y redistribución del poder que encuentra su justificación en las profundas transformaciones que ha sufrido la democracia en las últimas décadas».

47 Cfr. COSSío DÍAZ, José Ramón (et al.), El Poder Judicial de la Federación y los medios de comunicación. (Sentencias 18362001), Porrúa, México, 2002, pág. 109 y ss.

48 LOPEZ AYLLÓN, op. cit., pág. 9.

49 Así lo refería el artículo 61 de la Ley Federal de 2001 «El Poder Legislativo Federal, a través de la Cámara de Senadores, la Cámara de Diputados, la Comisión Permanente y la Auditoría Superior de la Federación; el Poder Judicial de la Federación a través de la Suprema Corte de Justicia de la Nación, del Consejo de la Judicatura Federal y de la Comisión de Administración del Tribunal Federal Electoral; los órganos constitucionales autónomos y los tribunales administrativos, en el ámbito de sus respectivas competencias, establecerán mediante reglamentos o acuerdos de carácter general, los órganos, criterios y procedimientos institucionales para proporcionar a los particulares el acceso a la información, de conformidad con los principios y plazos establecidos en esta Ley». 
En ese sentido para el Ejecutivo Federal el órgano garante comenzó a construir una serie de criterios, procedimientos y sobre todo bases firmes para lograr hacer efectivo en primerísimo lugar el derecho de acceso a la información y por supuesto generar una dinámica permanente y asertiva respecto a las obligaciones de transparencia que permitieran impactar en el derecho a la información en términos generales. Así el diseño institucional de este órgano garante supuso de inmediato la «manera en que los sujetos obligados por el derecho se organizan para poder responder a las solicitudes de acceso a la información que le hacen los ciudadanos» ${ }^{50}$ pero sobre todo hacerlos efectivos.

En términos de las obligaciones de transparencia el órgano garante propuso, de manera adecuada una serie de lineamientos, directrices e inclusive marcos metodológicos que permitieran a los sujetos obligados proponer mecanismos y procedimientos similares para transparentar la información ${ }^{51}$. Ello no permeó al derecho de acceso a la información pues a diferencia de lo que ocurría en materia de obligaciones de transparencia hubo casos en otros sujetos obligados fuera del Ejecutivo Federal en que los procedimientos para ejercer el derecho de acceso existían en papel pero no en la realidad ${ }^{52}$ haciendo nugatorio el acceso a la información del ciudadano.

Al igual que sucedía en términos de sujetos obligados de la administración federal en materia de sujetos obligados, en las entidades de la República se replicaba el fenómeno de manera más agravada. Si bien es cierto en los siguientes dos años de haber entrado en vigor la Ley Federal casi todas las entidades de la República contaba con leyes locales de transparencia y acceso a la información, se comenzaron a notar anomalías en cuanto su implementación generando un claro marco desigual respecto al ejercicio del derecho de acceso a la información ${ }^{53}$ Desde luego el problema fue agravándose pues la llamada autonomía de los órganos garantes estatales fue permanentemente vulnerada por los gobiernos tratando en ocasiones de imponer comisionados, amedrentándolos desde el poder público o simplemente impidiendo que los órganos de gobierno aperturaran la información o cumplieran con las obligaciones de transparencia.

Pronto en México nos encontramos con todo un sistema de transparencia y acceso a la información fuertemente viciado de origen, tanto por la falta de una adecuación constitucional que lo fortaleciera como con un reparto de competencias que, protegiendo el sistema federal en realidad propiciaba anomalías que impactaban en la adecuada garantía del derecho para el ciudadano.

\section{LOS RETOS DE LA NUEVA LEY GENERAL}

\section{a) Un paso previo}

Es imperante, antes de hablar de la nueva ley general decir que el tema constitucional fue superado en el año 2007. El asunto es relevantísimo dado que fue un paso de crucial importancia para las reformas del 2014 y 2015 en la materia. Sobre el particular quisiera abrir un pequeño espacio para que el lector pueda comprender con total conocimiento como se fue estructurando el cambio.

Como veníamos diciendo en el apartado anterior, uno de los principales problemas que enfrento el sistema de transparencia y el derecho de acceso a la información en México fue justamente que nació agarrado a la Constitución como se dice coloquialmente, "con alfileres». Aún y cuando hoy pensaríamos que la interpretación constitucional que hacía la Suprema Corte era más que suficiente, lo cierto es que en aquel entonces no bastaba para hacer del derecho de acceso un derecho de aplicación igualitaria para todos ${ }^{54}$. El reto era que la Constitución hablara expresamente del mismo y que dotara de mayor vigor a los órganos garantes para evitar las interferencias del poder.

50 LÓPEZ AYLLÓN, Sergio, "El acceso a la información como un derecho fundamental: la reforma al artículo 60 de la Constitución mexicana", Cuadernos de transparencia, INAI, México 2015, pág. 53 y ss.

51 Baste recordar el Marco metodológico del IFAI del año 2002 donde se sentaban las beses doctrinales y metodológicas de la construcción de toda la política pública en materia de transparencia y acceso a la información.

52 El caso más emblemático es el de la Cámara de Diputados de México que teniendo un reglamento que definía el procedimiento y los recursos al seno de dicha soberanía en realidad tardo en nombrar a los Consejeros de Transparencia casi un año para posteriormente no dotarlos de ninguna herramienta que les permitiera hacer efectivo dicho encargo obligándoles a desaparecer.

53 PESCHARD MARISCAL, Jacqueline, "A diez años del derecho de acceso a la información en México: Nuevos paradigmas para su garantía”, en PESCHARD MARISCAL, Jaqueline, A 10 años del derecho de acceso a la información en México, INAI, México, 2015, págs. 14 y 15.

54 Cfr. CARMONA TINOCO, Jorge Ulises, "El derecho de acceso a la información a la luz de la reforma en materia de derechos humanos", en PESCHARD, op. cit., págs. 33 y ss. 
Así se logró consensuar la reforma del artículo $6 .^{\circ}$ constitucional que fortaleció al derecho de acceso a la información de manera categórica. En dicha reforma se dejaron plasmados en rango constitucional los temas prototípicos de cualquier política pública en la materia y que si bien es cierto ya se encontraban contemplados en la Ley Federal ahora cobraban una fuerza determinante para tratar de obligar a todas las entidades federativas a llevar acciones que tendieran a vivir una adecuada vigencia del derecho de acceso Así lo narraba el dictamen de las Comisiones de Puntos Constitucionales y de la Función Pública en el análisis que hacía den la iniciativa de reforma:

La iniciativa que se dictamina, surge de un análisis pormenorizado y exhaustivo de una problemática nacional que no debemos aceptar: luego de cuatro años de marcha de las leyes de transparencia y acceso a la información, se ha cristalizado una heterogeneidad manifiesta y perjudicial de los cimientos para el ejercicio del derecho, que contienen diversas leyes, tanto federal como estatales ${ }^{55}$.

\section{b) Allanando el camino. Los primeros pasos hacia una Ley General de Transparencia}

Sin lugar a dudas esta reforma supuso un primer avance para superar las anomalías que se estaban generando en la implementación de las legislaciones en la materia. A pesar de lo positivo de la reforma no fue suficiente y las anomalías en la implementación seguían ocasionando una inadecuada garantía del derecho de acceso a la información en todo el país.

Con este paso previo y la necesidad de homogeneizar la forma en la que se estaba viviendo el derecho de acceso a la información fue de imperante necesidad buscar los consensos durante casi siete años para lograr superar esta crisis que en la materia se vivía. Para ello el camino no fue fácil. Por un lado pesaba mucho el tema del federalismo. Era muy complicado suponer que dotar al órgano garante Federal para implementar medidas en las entidades federativas no sería tomado como un atentado al pacto federal, por otro lado el pensar que se estandarizaran procesos o se creara una Plataforma Nacional de Transparencia insultaba el quehacer de todos los órganos garantes de las entidades federativas.

No obstante lo anterior durante años eran temas que se hablaban en todos los foros académicos vinculados a la materia en donde se alertaba de la urgente necesidad de proponer esquemas que propiciaran que el marco jurídico de la transparencia y el acceso a la información en el momento de su implementación no produjera los efectos nocivos que estaba produciendo.

En el camino, durante el año 2011, es importante referir que en México se produce una importantísima reforma en materia de derechos humanos. Esta reforma abre, entre otras cosas una nueva manera de entender los convenios internacionales en materia de derechos humanos trayendo a nuestro ordenamiento jurídico no sólo una apertura hacia ellos sino toda una tradición de interpretación constitucional conforme a los principios que se recogían en dichos instrumentos ${ }^{56}$.

Con todo este itinerario la urgencia por volver a reformar el sistema de transparencia y acceso a la información en México se volvió central. Aún y cuando el texto de la Constitución lo contemplaba y desarrollaba y aún y cuando la reforma de derechos humanos permitía un mayor activismo judicial en la materia, lo cierto es que existía un profundo desorden en cuanto su aplicación. Así, llegamos a una nueva reforma constitucional del año 2014 que abriría la puerta para trabajar la Ley General del año 2015, en donde se recogen todas estas preocupaciones tratándose de resolver.

\section{c) Los problemas concretos que enfrentaría una Ley General de Transparencia}

La reforma de 2014 pretendía atender ya en concreto las siguientes problemáticas.

a) «En el país existían 3 distintos procedimientos para sancionar incumplimientos: 1) de forma directa, 2) con vista a los órganos de control y 3) mixta (ambas formas).

55 Gaceta Parlamentaria Cámara de Diputados, núm. 2207-II, martes 6 de marzo de 2007. Dictamen de las comisiones unidas de Puntos Constitucionales y de la Función Pública, con proyecto de decreto por el que se reforma el artículo sexto de la constitución política de los estados unidos mexicanos.

56 Cfr. OROZCO HENRÍQUEZ, José de Jesús, "El derecho de acceso a la información y el sistema interamericano", en PESCHARD, op. cit., pág. 17. De igual manera se recomienda el trabajo de Saúl López Noriega en donde describe de manera atinada como la transparencia y el derecho de acceso a al información en México se alinean con la reforma en materia de derechos humanos del año 2011. Cfr. LOPEZ NORIEGA, Saúl, "Transparencia y el nuevo sistema de derechos humanos", INAI, Cuadernos de transparencia, 22, México, 2015. 
b) La mayoría de los órganos garantes no evaluaban el cumplimiento de la ley de forma sistemática y con criterios específicos.

c) La mayor parte de los órganos garantes no contaban con programas integrales de capacitación para servidores públicos.

d) Solo 11 entidades federativas de las 31 contaban con ley específica de protección de datos personales, además de la Ley Federal de Protección de Datos Personales en Posesión de Particulares.

e) El presupuesto asignado a los órganos garantes era muy dispar, mientras unos órganos reciben entre 1.79 y 2.16 pesos por habitante, otros recibían más de 20 pesos.

f) Respecto a las solicitudes de información, en 2013 solo cinco entidades concentraron el $63.5 \%$ del total de solicitudes; en cambio, 18 estados (la mitad) apenas alcanzaron el $17.1 \%$ del total.

g) El porcentaje de solicitudes con recursos de revisión oscilaba entre el rango de $0.1 \%$ y $18.2 \%$ (en 2013)» ${ }^{57}$.

Como podemos observar la implementación de toda la legislación en materia de transparencia por el país era completamente desigual y generaba muchas anomalías y diferencias. Estas diferencias producían efectos de desigualdad en cuanto el ejercicio del derecho de acceso que se fueron volviendo muy notorios con el paso del tiempo.

Se volvió sistemático el escuchar constantes quejas de los órganos garantes estatales sobre la intromisión del gobierno local respecto la resolución de recursos de revisión o bien a partir del no cumplimiento de sus resoluciones violentando sistemáticamente la autonomía operativa, de gestión y decisión que todo órgano garante debe poseer ${ }^{58}$.

Para ello el primer paso era lograr una nueva modificación constitucional que abriera la puerta para.

a) El fortalecimiento del órgano garante federal en el cual se liberara por completo del Ejecutivo Federal en cuanto a la designación de sus integrantes y que se incluyera la facultad de poder interponer controversias constitucionales ante la Suprema Corte de Justicia de la Federación ${ }^{59}$.

b) El fortalecimiento de los órganos garantes de los Estados para poder gozar de un mayor marco de autonomía respecto a los gobiernos estatales ${ }^{60}$

c) La inclusión de otros sujetos obligados como partidos políticos, sindicatos o personas físicas y morales que ejerzan gasto público ${ }^{61}$

d) La coordinación entre órganos garantes locales y el federal ${ }^{62}$

e) La creación del Sistema Nacional de transparencia ${ }^{63}$

Con esta importante reforma se pretendía abatir esas diferencias que hacían un ejercicio diferenciado del derecho de acceso a la información teniendo como eje central el fortalecimiento de los órganos garantes y sobre todo un esquema de coordinación sobre diversos criterios y procedimientos en la materia. Esta reforma constitucional abriría la puerta al Sistema Nacional de Transparencia que tendría como primer elemento de publicidad la Plataforma Nacional de Transparencia.

De igual manera había un descontento social sobre algunos «paraísos de opacidad» en donde toda la construcción anterior del sistema no irradiaba su luz. Así por ejemplo sindicatos que recibían estímulos del Estado o los mismos partidos políticos que si bien es cierto participaban de la transparencia a partir de un intermediario generaban mucha suspicacia sobre el manejo del dinero público ${ }^{64}$. Ya ni hablar sobre

${ }^{57}$ Cfr. GUERRA FORD, Oscar Mauricio, Reforma Constitucional de Transparencia y sus leyes reglamentarias, IFAl, Documento de trabajo - presentación, México, 2015. Este documento puede ser localizado en línea en la dirección: http://inicio.ifai.org.mx/presentaciones/Present_Reforma\%20y\%20leyes\%20grales_OMGF_230415.pdf. consultado por última vez por el autor de este trabajo el día 31 de Agosto del año 2016.

${ }^{58}$ Cfr. LOPEZ AYLLON, Sergio, op. cit., pág. 57. Es interesante como el autor refiere como una de las características vitales de estos órganos garantes a la independencia. Así refiere que la independencia del órgano garante es «...un mandato claro que busca asegurar la imparcialidad de sus decisiones e impedir la subordinación -jurídica, orgánica o política- a cualquier otra autoridad en el ámbito de su competencia. Para asegurar esta independencia, la Constitución les otorga tres autonomías específicas: operativa, de gestión y de decisión».

${ }_{59}$ Cfr. GUERRA FORD, op. cit., pág. 20.

60 Idem.

61 Idem.

62 Idem.

63 Idem.

${ }^{64}$ Cfr. PESCHARD, Jaqueline, "Transparencia y partidos políticos", Cuadernos de transparencia, 08, IFAl, México 2007, pág. 34 Así, refiere la autora que «La transparencia de los flujos de dinero en la política es esencial para ventilar las malas prácticas, y para 
los fideicomisos públicos los cuales amparados por el secreto bancario impedían observar el uso y destino de recursos del erario generando en muchos casos la utilización de la discrecionalidad del gobierno en turno.

\section{ACCESO A LA INFORMACIÓN Y TRANSPARENCIA PARA TODOS}

\section{a) Primer reto: Superar el fantasma del centralismo}

Con los problemas planteados en las líneas anteriores el proceso constitucional-legislativo sería sumamente complejo empezando por el miedo descrito con anterioridad a que el sistema de transparencia fuera señalado como un acto de la autoridad federal controlador y que pretendiera nulificar los esfuerzos que, en las entidades federativas, se estaban realizando ${ }^{65}$. Para ello era necesario que el llamado Sistema Nacional de Transparencia conjuntara los esfuerzos de todos y que tuviera como finalidad la mejora de prácticas y procedimientos en la materia con el único fin de garantizar de manera homogénea al ciudadano de todo el país el derecho de acceso a la información y la información pública que se transparentaba como obligación.

En ese sentido el fantasma del centralismo comenzó a disiparse a partir del marco competencial propuesto para el INAI así como el diseño institucional del sistema nacional de transparencia en donde participaban todos los órganos garantes del país. Para el primer caso, la autoridad federal sólo quedaría limitada a fungir como un segundo nivel de los recursos de revisión presentados por los particulares en los órganos garantes de las entidades federativas ${ }^{66}$. A ello dentro del sistema se le conoce como recurso de inconformidad. Con este recurso es claro que se buscaba por un lado homogeneizar criterios respecto a la clasificación de la información pero también librar a los órganos garantes de las entidades federativas de la permanente presión de los órganos de gobierno en las mismas.

Si bien es cierto era un claro fortalecimiento competencial del órgano federal, por las circunstancias que hemos descrito con anterioridad respecto a las entidades federativas, se entendió que de no lograr este consenso el futuro de la garantía del derecho de acceso a la información estaría encaminado al fracaso. Así, aún y cuando hubo reticencias, se pudieron superar bajo la óptica de una mejor implementación y garantía del derecho.

\section{b) Más información pública en posesión del ciudadano}

Si bien es cierto desde que se construyó el sistema de transparencia mexicano se acompañó al mismo del Principio de Máxima Publicidad el cual supone un grado mayúsculo de publicidad del Estado, también es cierto que con el diseño de la legislación federal que estuvo vigente los primeros años de vida del sistema y que orientó a todas las legislaciones estatales, sólo se contemplaron diecisiete obligaciones de transparencia, las cuales pretendían abarcar todo el quehacer de los sujetos obligados.

Con el pasar de los años y la experiencia que todos los órganos garantes del país, México se dio cuenta que era insuficiente una regulación de dichas obligaciones de la manera en la que se había realizado. En ese sentido el primer tema que debió ordenarse era una distinción simple que consistía en determinar cuales son las obligaciones comunes a todos los sujetos obligados y cuales son obligaciones específicas de los mismos sujetos. Así, la Ley General propuso un total de 170 obligaciones de transparencia de las cuales 48 fueron comunes y 122 fueron ya de carácter específico dependiendo del sector en el que se encuentren los sujetos ${ }^{67}$.

Este cambio sustancial propicia un mayor y mejor orden en todos los niveles de gobierno y sobre todo genera un impedimento de evasión por parte de los sujetos obligados. Era común escuchar a estos sujetos referir sobre determinada información que no era susceptible de transparencia pues no encontraban fun-

\footnotetext{
desde ahí, desalentarlas; para identificar a los donantes ocultos o a las contribuciones ilegales, como las provenientes del narcotráfico o del crimen organizado que de nueva cuenta fomentan la corrupción y socavan el estado de derecho».

65 CIRIO, Claudio, La amenaza al Sistema Nacional de Transparencia, RRC-CIDE, México 2015. Consultado en línea por última vez el día 28 de septiembre de 2016. http://rendiciondecuentas.org.mx/la-amenaza-al-sistema-nacional-de-transparencia/.

66 Así lo refiere el texto de la Ley General de Transparencia y acceso a la información en su artículo 159. «Tratándose de las resoluciones a los recursos de revisión de los Organismos garantes de las Entidades Federativas, los particulares podrán optar por acudir ante el Instituto o ante el Poder Judicial de la Federación».

${ }_{67}$ GUERRA FORD, op. cit., pág. 27.
} 
damento legal que los obligará. Esto hoy en México se ha superado no sólo por el incremento sustancial de obligaciones de transparencia sino también por la inclusión en la Ley General de lo que se denominó «transparencia proactiva» ${ }^{6}$.

A la par, es importante referir que este incremento de publicidad estatal abre inclusive la puerta en determinados casos a aspectos que antes quedaban vedados por la confidencialidad de la investigación ministerial o bien por la secrecía del expediente judicial. Nos referimos a los casos concretos de las violaciones graves de derechos humanos, delitos de lesa humanidad o cuando se trate de información relacionada con actos de corrupción. En estos tres no se podrá invocar el carácter reservado de la información ${ }^{69}$ De igual manera en la misma ley se precisaron conceptos tales como seguridad nacional y estabilidad financiera par impedir la ambigüedad y que ello pudiera generar situaciones de opacidad amparadas por un inadecuado fraseo de la ley ${ }^{70}$

\section{c) La concreción del acceso universal homogéneo: Plataforma Nacional de Transparencia}

Todo lo que hemos descrito en los apartados anteriores podría seguir generando los mismos vicios que se pretendían superar si no se generaba a la par un mecanismo que permitiera visualizar a todos la concreción del principio de máxima publicidad. En ese sentido el Sistema Nacional de Transparencia no sólo permitiría un diálogo abierto entre todos los participantes para un mejor desarrollo de la política pública en la materia sino también tendría como tarea fundamental concretar dicho diálogo en avances de la garantía de ese derecho. Para ello se crea la Plataforma Nacional de Transparencia.

Dicha plataforma como medio tecnológico logra el ideal de toda esta reforma. Conjuntar en un mismo espacio (en este caso virtual) los aspectos más relevantes que todo ciudadano puede necesitar para expandir al máximo sus derechos de acceder a la información y de recibir información ${ }^{71}$. Para ello, dicha plataforma conjunta cuatro elementos fundamentales:

a) Sistema de solicitudes de acceso a la información.

b) Sistema de gestión de medios de impugnación.

c) Sistema de portales de obligaciones de transparencia.

d) Sistema de comunicación entre organismos garantes y sujetos obligados.

En una sola plataforma el ciudadano podrá verificar de manera uniforme toda la información que de manera obligada tendrá que transparentar los llamados sujetos obligados de todo el país. Esto es un avance sustancial respecto a la tesis central de este artículo que es la homogenización. En el pasado si un ciudadano pretendía buscar información de diversos sujetos obligados en el país tenía que enfrentarse a la pulverización de procedimientos para transparentar la información y ya ni hablar de que en muchas realidades de las entidades federativas los portales de transparencia eran un desastre. Ahora la Plataforma impone un modelo único y concentra la información de todos.

A la par la plataforma desarrolla dos sistemas muy importantes: por un lado un sistema de gestión de medios de impugnación y por otro un sistema de solicitudes de información. Esto significa que desde la misma plataforma los ciudadanos de todo el país podrán presentar sus solicitudes de acceso y sus recursos de revisión en materia de transparencia de manera homogénea permitiendo ello no encontrarse con regímenes diferenciados para la tramitación tanto de solicitudes como de recursos. La plataforma permite que desde un mismo espacio se puedan gestionar tanto solicitudes de acceso como recursos de revisión en todas las entidades de la República y en todos los niveles competenciales y además bajo procedimientos estandarizados. Todo lo anterior trae beneficios notables para una mejor vivencia y sobre todo garantía del derecho de acceso a la información pública.

68 Por transparencia proactiva entendemos aquella diseñada para incentivar a los sujetos obligados a publicar información adicional a la que establece como mínimo la presente Ley. Así lo refiere el artículo 56 de la Ley General.

69 Así lo refiere la ley General en su artículo 115. «No podrá invocarse el carácter de reservado cuando: I. Se trate de violaciones graves de derechos humanos o delitos de lesa humanidad, o II. Se trate de información relacionada con actos de corrupción de acuerdo con las leyes aplicables».

70 Cfr. GUERRA FORD, op. cit., pág. 27.

71 Es importante hacer esta distinción entre acceder y recibir pues como sabemos en toda la doctrina de la Corte lberoamericana de derechos humanos, ambos derechos son derivados de la libertad de expresión y se manifiestan como facultades de la misma pero operan de manera diversa en el enramado de las libertades informativas. Al respecto se recomienda el documento: OEA, Marco Jurídico Iberoamericano de la libertad de expresión, CIDH, 2010. 


\section{IV. ¿A MAYOR ACCESO A LA INFORMACIÓN, MEJORES CIUDADANOS Y MEJOR GOBIERNO?}

El muestreo que hemos hecho en este apartado sólo es índicativo de los temas que nos parecieron los más relevantes pues hubo otros que se sumaron a esta importante reforma que permitió la homogenización del derecho de acceso a la información y por supuesto, como consecuencia una mejor garantía. Hoy según el Centre for law and democracy en el Global Right Information Rating coloca a México como número uno en materia de legislación que potencia la transparencia ${ }^{72}$.

Ante dicha transformación habría que preguntarnos entonces ¿Cuál es la razón por la cual México sigue presentándose como un país donde hay una tasa alta de corrupción ${ }^{73}$ según los datos internacionales arrojados por organizaciones no gubernamentales que siguen las pistas sobre los países más corruptos.

La respuesta se encuentra en el diseño mismo del sistema mexicano: Mayor transparencia no significa necesariamente mejor rendición de cuentas. La transparencia es sólo una parte de la rendición de cuentas la cual debe venir siempre acompañada de procesos de fiscalización y de procesos de anticorrupción. Proponer un sistema de rendición de cuentas en donde la única figura concreta sea la política de transparencia o el derecho de acceso a la información es dejar cojo al mismo sistema.

Una adecuada implementación de rendición de cuentas para tener un eficaz control ciudadano del quehacer gubernativo se encontrará depositado en los tres apartados mencionados anteriormente pues de lo contrario pasará lo que ha venido sucediendo en México en los últimos años, es decir tener leyes de avanzada en materia de transparencia y seguir viviendo un clima de impunidad respecto a actos de gobierno completamente deleznables por corruptos.

A la par de lo anterior, la llamada socialización de la política de transparencia y del derecho de acceso a la información se ha visto menoscabada en México por la disparidad en cuanto a procedimientos, criterios y selección de autoridades que garanticen e impulsen la política. Lo que apareció como una novedad en el $2001^{74}$ se ha visto afectado por un desencanto de la población que observa a la transparencia como un discurso vacío al seguir resintiendo los efectos de la impunidad cuando existen casos de corrupción. No es gratuito que el Estado Mexicano haya apuntalado en los últimos dos años políticas tendientes a un mejor sistema de fiscalización y a un mejor y más eficaz sistema anticorrupción donde la impunidad sea erradicada. Veremos si esto puede acompañar al sistema de transparencia estando a la altura del mismo.

De igual manera es importante recalcar que los mecanismos de acceso a la información y la obligación de transparencia siguen teniendo un bajo impacto en la dinámica social en clave de utilización del ciudadano «de a pie». Esto significa que teniendo legislación de primera dicho ciudadano no acaba de familiarizarse con el sistema como un mecanismo que le ayude a tomar mejores decisiones públicas. El error del Estado Mexicano en este tenor sigue siendo que la transparencia de la información debe quedarse sólo en ese nivel y no existen, al menos en los últimos esfuerzos, indicativos que nos permitan suponer que ello cambiara. Transparentar información de nada basta si no logramos convertir esa información en conocimiento.

Lo anterior es el siguiente nivel de la información transparente. El ciudadano ha obtenido un triunfo significativo en cuanto la publicidad de la información estatal pero hoy ese ciudadano, ante el maremoto de información, no tiene herramientas para traducir la misma en un conocimiento asertivo. En poco tiempo México pasará de tener una ley de avanzada y catalogada como número uno en el mundo a ser un ejercicio mediocre de transparencia que no le otorga un valor agregado a su información traduciéndola en conocimiento útil para el ciudadano.

\section{CONCLUSIONES}

El derecho de acceso a la información es un derecho que abona a la construcción del espacio público. Sin este derecho el ciudadano quedaría sin la posibilidad de acudir directamente a la fuente original de la información quedando a merced de los intermediarios de la misma. Sin este derecho pensar en una opinión pública activa, deliberante, crítica y dialogante sería una mera ilusión.

72 Consultado en http://www.rti-rating.org/. Ultima fecha de visita fue el 29 de septiembre de 2016.

73 Según el Informe sobre la percepción de la corrupción 2015 publicado por Transparencia Internacional en el 2016 , México sólo obtuvo 35 puntos sobre 100 en materia de corrupción colocándose en niveles críticos referidos a esta actividad. http://www.transparency.org/cpi2015\#map-container consultado por última ocasión el día 29 de septiembre del 2016.

74 No sólo como una novedad graciosa, sino como un movimiento intelectual, social y político. Cfr. PLA LUNA, op. cit., pág. 49 y ss. 
El derecho de acceso a la información posibilita una sociedad democrática abierta en donde el titular del derecho encuentra una herramienta lo suficientemente fuerte y protegida para vincularse con los asuntos públicos. Una herramienta construida para protegerlo en lo individual y potenciar su espíritu comunitario. Una herramienta vinculada y construida sobre principios que orientan su actuar para la consecución de un mejor y mayor desenvolvimiento en lo público.

Se observa un crecimiento similar de la transparencia y el acceso a la información en toda la región Iberoamericana a partir de principios y procedimientos comunes que en mayor o menor medida se asientan en los cuerpos legislativos de todos los países.

Se presenta como caso de estudio la evolución del sistema de transparencia y del derecho de acceso a la información en México en los últimos quince años a partir del concepto de homogenización de procedimientos en donde hemos visto que, a pesar de ser un largo recorrido, al menos en papel, aquel país ha logrado una ley modelo que puede servir de orientación a otros países.

Se destacó la importancia de la reforma constitucional de 2014 y de la consecuente Ley General de Transparencia en dicha homogenización pues ambas permitieron superar la crisis que vivía la materia potenciando un nuevo marco jurídico más completo y como mejores posibilidades de garantizar el derecho de acceso a la información.

De igual manera observamos que en México la mejora del sistema de transparencia no viene acompañada de una mejora en cuanto a la reducción de los niveles de corrupción en función de un asimétrico trabajo en materia de la integralidad de la rendición de cuentas encontrándonos con un papel protagónico en materia de transparencia pero con un bajo nivel o casi inexistente en materia de fiscalización y anticorrupción.

\section{BIBLIOGRAFÍA}

ARENDT, Hannah, La condición Humana, Paidos, Madrid.

AZURMENDI, Ana, "La libertad de expresión en la jurisprudencia de la Corte Interamericana de Derechos Humanos: La influencia del tribunal europeo de derechos del hombre", en TENORIO CUETO, Guillermo, La libertad de expresión y sus fronteras contemporáneas, Porrúa-UP, México, 2007.

BALTAZAR MACÍAS, Atzimba, GUERRERO AMPARÁN, Juan Pablo, "El Instituto Federal de acceso a la información pública: La construcción institucional”, en CONCHA CANTÚ, Hugo, et al. (coords.), Transparentar al Estado: la experiencia mexicana de acceso a la información, IIJ-UNAM, México, 2005.

BUSTILLOS ROQUEÑI, Jorge, "Máxima publicidad y reserva de la información como excepción", en CARBONELL, Miguel, Hacia una democracia de contenidos. La reforma constitucional en materia de transparencia, UNAM-IFAIINFODF, México, 2007.

CARMONA TINOCO, Jorge Ulises, "EI derecho de acceso a la información a la luz de la reforma en materia de derechos humanos", en PESCHARD, Jacqueline, A 10 años del derecho de acceso a la información en México: Nuevos paradigmas para su garantía, INAI, México, 2015.

CIRIO, Claudio, La amenaza al Sistema Nacional de Transparencia, RRC-CIDE, México 2015. Consultado en línea por última vez el día 28 de septiembre de 2016. http://rendiciondecuentas.org.mx/la-amenaza-al-sistema-nacional-detransparencia/.

COSSíO DÍAZ, José Ramón (et al.), El Poder Judicial de la Federación y los medios de comunicación. (Sentencias 1836-2001), Porrúa, México, 2002.

FAÚNDEZ LEDEZMA, Los límites de la libertad de expresión, IIJ-UNAM, México, 2004.

FERNÁNDEZ RAMOS, Severiano, El derecho de acceso a los documentos administrativos, Marcial Pons, Madrid, 1997.

GUERRA FORD, Oscar Mauricio, Reforma Constitucional de Transparencia y sus leyes reglamentarias, IFAI, Documento de trabajo - presentación, México, 2015. Este documento puede ser localizado en línea en la dirección: http://inicio.ifai.org.mx/presentaciones/Present_Reforma\%20y\%20leyes\%20grales_OMGF_230415.pdf consultado por última vez por el autor de este trabajo el día 31 de Agosto del año 2016.

GUTIÉRREZ COLANTUONO, Pablo Ángel, "El acceso a la información pública - Una doble mirada convencional y del derecho argentino", en VALIM, Rafael, et al. (coords.), Acesso à informacão pública, FORUM, Belo Horizonte, 2015.

HABERMAS, Jürgen, Historia y crítica de la opinión pública, Gili, Barcelona, 2004.

LÓPEZ AYLLÓN, Sergio, La creación de la Ley de Acceso a la Información en México: Una perspectiva desde el Ejecutivo Federal, IIJ UNAM, México, 2004.

-, "El acceso a la información como un derecho fundamental: la reforma al artículo 60 de la Constitución mexicana", Cuadernos de transparencia, INAI, México 2015.

- Democracia y Acceso a la Información, Colección de cuadernos Divulgación sobre Aspectos doctrinarios de la Justicia electoral, núm. 9, edit. Tribunal Electoral del Poder Judicial de la Federación, México, 2005. 
LOPEZ NORIEGA, Saúl, "Transparencia y el nuevo sistema de derechos humanos", INAI, Cuadernos de transparencia 22, México, 2015.

LUNA PLA, Issa, Movimiento social del derecho de acceso a la información en México, IIJ UNAM, México, 2009.

MARISCAL, Jaqueline, A 10 años del derecho de acceso a la información en México, INAI, México, 2015.

NAVA GOMAR, Salvador, "Información Reservada", en VILLANUEVA, Ernesto y LUNA PLA, Issa, Derecho de acceso a la información pública. Valoraciones iniciales, IIJ-UNAM, México, 2004.

NOELLE-NEUMANN, Elizabeth, La espiral del silencio. Opinión pública nuestra piel social. PAIDOS, Buenos Aires, 1995.

OROZCO HENRÍQUEZ, José de Jesús, "El derecho de acceso a la información y el sistema interamericano", en PESCHARD, Jacqueline, A 10 años del derecho de acceso a la información en México: Nuevos paradigmas para su garantía, INAI, México, 2015.

PESCHARD, Jaqueline, "Transparencia y partidos políticos", Cuadernos de transparencia, 08, IFAI, México 2007, pág. 34.

PESCHARD MARISCAL, Jacqueline, "A diez años del derecho de acceso a la información en México: Nuevos paradigmas para su garantía”, en PESCHARD MARISCAL, Jacqueline (coord.), A 10 años del derecho de acceso a la información en México: Nuevos paradigmas para su garantía, INAI, México, 2015.

ROMERO COLOMA, Aurelia María, Derecho a la Información y libertad de Expresión, edit. Bosh, Barcelona, 1984.

SAHUí, Alejandro, Razón, espació público en Habermas, Arendt y Rawls, Fontamara, México.

UVALLE BERRONES, Ricardo, La teoría de la razón de Estado y la administración pública, PyV editores, México, 1993.

VALDERRAMA CABRERA, Marcela, La reconstrucción de la información, Tesis de grado de Maestría en Derecho Administrativo, Universidad Panamericana, México, 2014.

VILLANUEVA, Ernesto, Temas selectos de derecho de la información, IIJ-UNAM, México, 2004.

VILLANUEVA, Ernesto, Derecho de acceso a la información pública en Latinoamérica, IIJ-UNAM, México, 2003.

WEBER, Max, ¿Qué es la burocracia?, Ediciones Coyoacán, México, 2004.

Corte Interamericana de Derechos Humanos, caso Gomes Lund y otros vs Brasil, parr. núm. 202.

\section{Documentos internacionales}

CIDH, El derecho de acceso a la información pública en las Américas. Estándares Interamericanos y comparación de marcos legales, Relatoría especial para la libertad de expresión. OEA, 2012.

CIDH, Caso Gomez Lund y otros vs Brasil, de 24 de noviembre de 2010.

$\mathrm{CIDH}$, caso Claude Reyes vs Chile, parr. n. ${ }^{\circ} 77$.

IFAI, Información, accesibilidad, diversidad e interacción, México, 2011.

OEA, El derecho de acceso a la información pública en las Américas. Estándares interamericanos y comparación de marcos legales, Relatoría especial para la libertad de expresión - CIDH, 2012.

OEA, Marco jurídico interamericano de la libertad de expresión, Relatoría especial para la libertad de expresión, OEA, 2010.

\section{Otros documentos consultados}

Marco metodológico del IFAI del año 2002.

OEA, Marco Jurídico Iberoamericano de la libertad de expresión, CIDH, 2010.

Ranking de legislación de transparencia. http://www.rti-rating.org/. Última fecha de visita fue el 29 de septiembre de 2016. Informe sobre la percepción de la corrupción 2015 publicado por Transparencia Internacional en el 2016. http://www. transparency.org/cpi2015\#map-container consultado por última ocasión el día 29 de septiembre del 2016. 